\title{
Clinical and histopathological characteristics of patients with incidental and nonincidental thyroid cancer
}

\author{
Krzysztof Kaliszewski ${ }^{1}$, Dorota Diakowska², Marta Strutyńska-Karpińska ${ }^{1}$, Beata Wojtczak
} Paweł Domosławski ${ }^{1}$, Waldemar Balcerzak ${ }^{1}$

\author{
${ }^{1} 1^{\text {st }}$ Department and Clinic of General, Gastroenterological and Endocrine Surgery, \\ Wroclaw Medical University, Wroclaw, Poland \\ ${ }^{2}$ Department and Clinic of Gastrointestinal and General Surgery, Wroclaw Medical \\ University, Wroclaw, Poland
}

Submitted: 9 July 2015

Accepted: 24 August 2015

Arch Med Sci 2017; 13, 2: 390-395

DOI: https://doi.org/10.5114/aoms.2016.59579

Copyright (c) 2016 Termedia \& Banach

\section{Abstract}

Introduction: Thyroid nodules (TNS) are a common pathology. Their prevalence increases with age. Some of them are suspected of malignancy and qualified for surgery. Sometimes their malignant nature is detected incidentally after a surgical procedure. The aim of the study is to analyze clinical and histopathological characteristics of patients with incidental and nonincidental thyroid carcinoma (ITC vs. NITC).

Material and methods: The case records of 3,241 patients with solitary and multiple TNs who were treated consecutively between 2008 and 2014 were analyzed retrospectively. After the final selection 235 (7.25\%) patients were included in the study (202 females and 33 males, mean age: $52.9 \pm 16.5$ years). Seventy-five (31.91\%) cases were incidentally diagnosed and 160 (68.09\%) were diagnosed before surgery.

Results: We did not observe any differences in age, gender or stage of disease at the time of diagnosis between the patients with ITC and NITC ( $p=$ $0.366, p=0.850, p=0.226$ respectively). The occurrence of solitary nodules in patients with NITC was significantly higher compared to patients with ITC $(p<0.0001)$. There were no differences in histopathological types of thyroid cancer (TC). The logistic regression analysis showed that solitary TC was an independent predictor of NITC $(p<0.0001)$.

Conclusions: There are no differences in gender, age or histopathological type of cancer in patients with ITC and NITC. Papillary TC is the predominant type in both groups. Incidence of TC in a solitary nodule is significantly higher in NITC than ITC. Solitary type of TC is an independent predictor of NITC. The prevalence of ITC is associated with multifocal type of TC.

Key words: thyroid nodules, incidental, non-incidental thyroid carcinoma.

\section{Introduction}

Thyroid nodules (TNs) are a very common pathology in the general population. They are found in $19-67 \%$ by means of ultrasonography examination [1]. Their detection is increasing with the widespread use of this diagnostic method [2]. Although there is not a recommendation for or against thyroid ultrasound screening for clinically silent thyroid lesions in individuals without any risk of malignancy, it can be observed that ultrasonography examination is widespread and accessible, so in the

\author{
Corresponding author: \\ Krzysztof Kaliszewski MD \\ $1^{\text {st }}$ Department and Clinic \\ of General, \\ Gastroenterological \\ and Endocrine Surgery \\ Wroclaw Medical University \\ 66 Sklodowskiej-Curie St \\ 50-369 Wroclaw, Poland \\ Phone: +48 601303999 \\ E-mail: krzysztofkali@wp.pl
}


majority of asymptomatic individuals TNs are diagnosed [3, 4]. Anil et al. [5] noticed the phenomenon that replacing palpating examination with an ultrasonography probe in elderly patients would result in "an epidemic" of TNs.

No imaging modality can accurately predict the nature of every nodule, and none of the ultrasonography characteristics have $100 \%$ accuracy in detecting or excluding thyroid cancer (TC) [6]. The discovery of the nodule leads to the next step of tumor evaluation and thyroid stimulating hormone (TSH) measurement is recommended. If TSH levels are not suppressed, then fine needle aspiration biopsy (FNAB) is performed. It has been claimed that the increasing use of FNAB with high-resolution ultrasonography makes thyroid malignancy diagnosis more frequent and at an earlier stage of disease [7]. Papini et al. suggest [8] that this is one reason why in the last decade we can observe smaller sizes of newly diagnosed TCS [8]. Some authors suggest that the risk of malignancy in patients with multinodular goiter is very high and unsuccessful, inconclusive or suspicious results of FNAB mandate further investigation [9]. For example, Campbell et al. [10] state that the incidence of TC in patients with multinodular goiter and the "negative" result of FNAB (without suspicion of malignancy) is significant [10]. The same authors suggest that all "negative" specimens obtained from the FNAB procedure in patients with multinodular goiter should be reviewed by an experienced cytopathologist to reduce the risk of undetected TC.

During the last 20 years in Poland a significant increase in the number of new cases of TC has been observed. In 2010 we recorded 2192 new cases of TC [11]. Especially, a lot of small TCs, known as microcarcinomas, are diagnosed after surgery performed for benign thyroid pathology. Such tumors are called incidental thyroid cancers (ITCS), and if they are smaller than or equal to $1 \mathrm{~cm}$ they are called incidental microcarcinomas [12]. Many authors agree that smaller TCs have a better prognosis than larger ones [13], but it must be remembered that some very small TCs, even less than $1 \mathrm{~cm}$ in diameter, have an unfavorable prognosis [14]. Some authors call these very aggressive tumors "real thyroid carcinoma" $[15,16]$.

Many patients are qualified for surgery due to solitary or multiple thyroid nodules with or without suspicion of malignancy. The incidence of carcinoma in TNs is approximately estimated as $9.2-13 \%[8,17,18]$. Some authors suggest that the presence of multifocal nodules decreases the possibility of incidence of TC [19]. In multinodular goiter the most suspicious nodules for TC are those with high-risk sonographic features, and for that reason they should be aspirated [1]. Others say that the prevalence of TC in patients with nonpalpable or incidentally diagnosed as TNs is the same as in those with palpable tumors $[8,18,20]$. On the other hand, when we compare the prevalence of TNs and the prevalence of ITC, we can describe this malignancy as a rare occurrence [5].

The most common type of this malignancy is papillary carcinoma, which accounts for about 85$90 \%$ of all TCs [21]. Papillary TC has a good prognosis and its mortality rate is less than 10\% [22]. Other types include follicular, medullary and anaplastic cancers. The mortality and morbidity rates of papillary TC are low compared to other cancers, but they increase with age and stage of the disease at the time of the diagnosis [23]. There is a debate regarding the clinical significance of small thyroid carcinomas, and most authors suggest that they represent a subclinical disease with no mortality or morbidity and propose a conservative approach such as follow-up and not surgery [24].

Because of the fact that in the very near future we may observe high prevalence of ITC, it seems very important and useful to establish whether there are any clinical and histopathological differences in patients with ITC and nonincidental thyroid carcinoma (NITC).

To evaluate this issue we analyzed retrospectively the medical documentation of patients with ITC and NITC.

\section{Material and methods}

The case records of 3,241 patients with solitary and multiple TNs, who were treated consecutively between January 2008 and December 2014 at the Department and Clinic of General, Gastroenterological and Endocrine Surgery of Wroclaw Medical University, were analyzed retrospectively. After the final selection, 235 (7.25\%) patients were included in the study. There were 202 females and 33 males, with a mean age of $52.9 \pm 16.5$ years. In this TC group 75 (31.91\%) patients had ITC and $160(68.09 \%)$ had NITC. We analyzed and compared the clinical and histopathological characteristics of patients with ITC and NITC. All patients lived before the operation in geographical areas that were iodine sufficient. All patients included in the study had FNAB performed before surgery. All cytological and next histopathological specimens were reviewed by an experienced pathologist, and final diagnoses were graded according to the World Health Organization thyroid malignancy classification.

\section{Statistical analysis}

The numbers and percentages were calculated for qualitative variables, and the means and standard deviations were calculated for quantitative 
variables. Where appropriate, groups comparisons were analyzed using the $\chi^{2}$ test and Student's $t$-test.

The logistic regression analysis was used for the determination of independent predictors of NITC for solitary TNs, multifocal TNs, female gender and age below 45 years. Odds ratios and $95 \%$ coefficient intervals $(95 \% \mathrm{Cls})$ were calculated.

All values of $p<0.05$ were considered statistically significant. The statistical analyses were performed using Statistica 10.0 software (StatSoft Inc., Tulsa, OK, USA).

\section{Results}

Among 3,241 patients operated on for thyroid nodules, 160 (4.94\%) had TC diagnosed before surgery (NITC group) and 75 (2.31\%) had TC diagnosed by postoperative histopathological examination (ITC group). Among 235 TC subjects, the rate of NITC patients (68.1\%) was twice as high as the number of patients with ITC (31.9\%).

Demographic and clinicopathological characteristics of patients with ITC and NITC are demonstrated in Table I. Incidental thyroid cancers and NITC groups were similar in terms of gender, age and histological type of cancer. Papillary TC was predominant, and it was diagnosed in $84.8 \%$ of patients with NITC and in $82.7 \%$ of patients with ITC. Incidence of solitary nodules in patients with NITC was significantly higher in comparison to ITC patients $(p<0.0001)$. The number of radical procedures (total thyroidectomy) performed in the group of patients with NITC was significantly higher than in the ITC group ( $p<0.0001)$, so the number of required reoperations in the ITC group was significantly higher than in the NITC group $(p<0.0001)$.

There were no differences between study groups in terms of stage of disease and primary tumor progression $(p>0.05)$. Exclusion of metastases to lymph nodes and other organs was mainly demonstrated in patients with NITC ( $p<$ 0.0001 ). The pathological $N$ parameter has not been determined in over $90 \%$ of patients with ITC. Therefore, the interpretation of results presented in Table I is uncertain.

Logistic regression analysis was used to determine which demographic and clinical parameters may be associated with TC diagnosis before surgical treatment. The results confirmed that solitary type of TC was an independent predictor of NITC, and that prevalence of ITC is connected with type of multifocal TC ( $p<0.0001$ for both, Table II).

\section{Discussion}

Since 1980, when ultrasonography examination and ultrasound guided FNAB (UG-FNAB) were widely introduced to clinical evaluation of thyroid pathology, a progressive increase in the prevalence of ITC has been observed [25]. Some authors estimated ultrasound features of increased malignancy risk of thyroid nodules, such as microcalcifications, low echogenicity of lesions or predominance of the anterior-posterior dimension over the lateral dimension of lesions [1, 4, 26, 27]. In the opinion of many authors, large nodules or dominant ones have higher risk for malignancy than small lesions, but it is not the rule. Some, very small nodules might turn out to be microcarcinomas and be discovered after surgery as ITC. Pelizzo et al. [28] noted that the prevalence of carcinoma less than or equal to $5 \mathrm{~mm}$ compared with those measuring 6-10 $\mathrm{mm}$ increased in the period between 1990 and 2001. The same situation might exist in the remaining TCs, larger than $1 \mathrm{~cm}$ in diameter. The majority of them are diagnosed as ITC, so some authors try to estimate the clinical factors of high risk for malignancy of TNs [1, 4, 29 , 30]. The most often analyzed are age, gender, type of thyroid nodule (solitary or multiple), enlarged lymph nodes and diameter of the tumor. If there are any suspicions of malignancy in some nodules (lymph node involvement, ultrasound features of increased malignancy risk or high blood level of calcitonin), each of them should be further evaluated and UG-FNAB should be performed [1, 4, 29].

In our study we analyzed retrospectively 3,241 patients surgically treated due to TNs. Among them we identified 235 (7.25\%) cases with TC. The prevalence of ITC was lower than that observed in some other studies [31], and in our study it was estimated at $2.3 \%$. These differences probably are due to different geographical regions, populations, ultrasound examination accuracy and reliability of FNAB. ITCS are in the great majority papillary type, and a lot of them are less than $1 \mathrm{~cm}$ in diameter. In our study in the group of patients with ITC papillary type occurred in 62 (82.7\%) patients, and in the group with NITC this type occurred in 134 (84.8\%) cases. We also did not observe a statistically significant difference in tumor size of ITC and NITC. In the ITC group the majority of nodules were below stage pT1b (according to AJCC/ UICC $20107^{\text {th }}$ Edition) (51; 70.8\%), and in the NITC group there were 103 (65.0\%) such nodules $(p>0.05)$. Most ITCs are diagnosed after surgery due to multinodular goiter, fewer due to other benign thyroid pathologies. In our study we found that solitary TN is an independent predictor of TC presence, so this characteristic was observed more often in patients with NITC compared to patients with ITC ( $85 \%$ vs. $38.7 \%$ respectively, $p<0.0001)$.

Some authors suggest that small ITCs have benign behavior and will never spread to the regional or distant lymph nodes or organs [32]. In contrast, others have described very small TCs, 
Table I. Demographic and clinicopathological characteristics of patients with incidental and nonincidental thyroid cancer (TC). Descriptive data are presented as number (percent)

\begin{tabular}{|c|c|c|c|c|}
\hline Parameter & $\begin{array}{c}\text { Incidental TC } \\
(n=75)\end{array}$ & $\begin{array}{c}\text { Nonincidental TC } \\
(n=160)\end{array}$ & $\chi^{2}$ test & $P$-value \\
\hline Age: & & & 0.82 & 0.366 \\
\hline$<45$ & $20(26.7)$ & $52(32.5)$ & & \\
\hline$\geq 45$ & $55(73.3)$ & $108(67.5)$ & & \\
\hline Gender: & & & 0.04 & 0.850 \\
\hline Female & $64(85.3)$ & $138(86.2)$ & & \\
\hline Male & $11(14.7)$ & $22(13.8)$ & & \\
\hline Type of thyroid nodules: & & & 52.41 & $<0.0001$ \\
\hline Solitary & $29(38.7)$ & $136(85)$ & & \\
\hline Multifocal & $46(61.3)$ & $24(15)$ & & \\
\hline Type of resection: & & & 92.91 & $<0.0001$ \\
\hline Radical & $16(21.3)$ & $137(85.6)$ & & \\
\hline No radical & $59(78.7)$ & $23(14.4)$ & & \\
\hline Reoperation needed: & & & 113.02 & $<0.0001$ \\
\hline No & $17(22.7)$ & $146(91.3)$ & & \\
\hline Yes & $58(77.3)$ & $14(8.7)$ & & \\
\hline Type of cancer: & & & 1.719 & 0.787 \\
\hline Papillary & $62(82.7)$ & $134(84.8)$ & & \\
\hline Follicular & $8(10.7)$ & $10(6.3)$ & & \\
\hline Medullary & $2(2.7)$ & $5(3.2)$ & & \\
\hline Undifferentiated & $2(2.7)$ & $7(4.4)$ & & \\
\hline Sarcoma & $1(1.3)$ & $2(1.3)$ & & \\
\hline pTNM stage: & & & 4.34 & 0.226 \\
\hline I & $53(70.7)$ & $107(66.9)$ & & \\
\hline II & $14(18.7)$ & $22(13.8)$ & & \\
\hline III & $6(6.7)$ & $12(7.5)$ & & \\
\hline IV & $3(4.0)$ & 19 (11.9) & & \\
\hline pT: & & & 8.70 & 0.121 \\
\hline pT1a & $36(50)$ & $60(38.0)$ & & \\
\hline pT1b & $15(20.8)$ & $43(27.0)$ & & \\
\hline pT2 & $11(15.3)$ & $24(15.2)$ & & \\
\hline pT3 & $7(9.7)$ & $10(6.3)$ & & \\
\hline pT4a & $0(0.0)$ & $11(7.0)$ & & \\
\hline pT4b & $3(4.2)$ & $10(6.3)$ & & \\
\hline pN: & & & 140.04 & $<0.0001$ \\
\hline $\mathrm{pNO}$ & $4(5.3)$ & $106(66.3)$ & & \\
\hline $\mathrm{pN} 1 \mathrm{a}$ & $1(1.3)$ & $23(14.4)$ & & \\
\hline pN1b & $1(1.3)$ & $12(7.5)$ & & \\
\hline $\mathrm{pNx}$ & $69(92.0)$ & 19 (11.9) & & \\
\hline pM: & & & 144.03 & $<0.0001$ \\
\hline $\mathrm{pMO}$ & $5(6.7)$ & $136(85.0)$ & & \\
\hline $\mathrm{pM} 1$ & $0(0.0)$ & $5(3.1)$ & & \\
\hline $\mathrm{pMx}$ & $70(93.3)$ & 19 (11.9) & & \\
\hline
\end{tabular}


Table II. Logistic regression model assessing independent predictors of thyroid cancer (TC) presence (NITC/ITC, 1/0). Total: $\chi^{2}=53.28, p<0.0001$

\begin{tabular}{|lcccc|}
\hline Variables & OR & $95 \% \mathrm{Cl}$ & Wald test & $P$-value \\
\hline Type of thyroid nodules: for solitary & 8.88 & $4.63-17.02$ & 43.65 & $<0.0001^{*}$ \\
\hline Type of thyroid nodules: for multifocal & -2.22 & $-2.87-(-1.58)$ & 45.91 & $<0.0001^{*}$ \\
\hline Gender: for female & 0.94 & $0.37-2.37$ & 0.02 & 0.895 \\
\hline Age: for $<45$ years & 1.60 & $0.77-3.33$ & 1.60 & 0.206 \\
\hline
\end{tabular}

NITC - non-incidental thyroid cancer, ITC - incidental thyroid cancer, * statistically significant.

less than $1 \mathrm{~cm}$ in diameter, that gave local lymph node and distant metastases at the time of diagnosis $[25,33,34]$. In our study the prevalence of lymph node involvement was significantly higher in the group of patients with NITC compared to the group with ITC $(p<0.0001)$.

Pellegriti et al. [21] emphasize that some ITCS and NITCs have clinical and histopathological characteristics which determine poor prognosis. The most important are age of the patient at the time of TC diagnosis, nodule size, lymph node involvement and the presence of distant metastases. The nodule size in ITC is a very important prognostic factor. A lot of studies report low cancer recurrence rates in patients with low histopathological degree, especially less than $\mathrm{pT} 1 \mathrm{~b}[28,33$, 35-37]. Of course, there are some others who do not confirm this observation [21, 25]. Disease-related mortality has been observed very rarely $[25$, 35]. Multifocality and dimensions of ITC are also very important information, because according to them, further evaluation is planned.

In our study we noted that multifocality was observed more often in patients with ITC than in patients with NITC (61.3\% vs. $15 \%)$. We did not observe significant differences in age, gender or stage of disease at the time of diagnosis between groups. Some authors emphasize a very important aspect of multifocality of ITC $[33,34]$. They suggest that this specific feature may be connected with aggressiveness of this tumor. However, others have demonstrated that various intrathyroidal carcinoma foci had different RET/PTC gene rearrangements and independent clonal origins. It rather suggests that they arise as distinct tumors [38]. Some authors confirm our results and report higher prevalence of multifocality (32-40\%) in ITCs [21, 25].

In our study the prevalence of NITC was two times higher than ITC (31.91\% vs. 68.09\%). In the opinion of some researchers, this situation is caused by the phenomenon of overdiagnosis of TC [39]. They noted that TC fulfills all criteria for overdiagnosis, but they also added that this is supported by the geographical region where the analyzed population lives.

It is still a matter of debate what surgical procedure is sufficient for ITC. Ito et al. [32] reported their own 3.8-year observation period of the non-oper- ated patients with proven papillary thyroid carcinoma at a stage below pT1b. During this period they did not develop any sign of progression. In our study papillary type was dominant in patients with ITC (82.7\%). Some authors suggest that surgery extension is not crucial in patients with a tumor at a stage below pT1b [32]. Other researchers propose partial thyroidectomy as a sufficient surgical procedure in cases of ITC but with a tumor at a stage below pT1b [37]. Others say that total or near total thyroidectomy in patients with ITC should be performed $[21,25,28]$. In our study in the group of patients with ITC we performed 16 (21.3\%) radical (total thyroidectomy) and 59 (78.7\%) non-radical procedures (subtotal thyroidectomy). After histopathological examination 58 (77.3\%) individuals with ITC needed reoperation due to an insufficient primary procedure. Therefore some authors suggest that total thyroidectomy may be considered as the treatment of choice for both malignant and benign thyroid disease [40]. They add that total thyroidectomy eliminates the risk of completion thyroidectomy for ITC.

In conclusion, there are no differences in gender, age or histopathological type of cancer in patients with ITC and NITC. Papillary TC is the predominant type in patients with ITC and NITC. Incidence of TC in a solitary nodule is significantly higher in patients with NITC compared to ITC. Solitary type of TC is an independent predictor of NITC. The prevalence of ITC is associated with multifocal type of TC.

\section{Conflict of interest}

The authors declare no conflict of interest.

\section{References}

1. Cooper DS, Doherty GM, Haugen BR, et al. Revised American Thyroid Association management guidelines for patients with thyroid nodules and differentiated thyroid cancer. Thyroid 2009; 19: 1167-214.

2. Remonti LR, Kramer CK, Leitao CB, Pinto LC, Gross JL. Thyroid ultrasound features and risk of carcinoma: a systematic review and meta-analysis of observational studies. Thyroid 2015; 25: 538-50.

3. Yuen YH, Tong CLS, Ahuja AT. Sonography of the normal thyroid. In: Ultrasound of the thyroid and parathyroid glands. Sofferman RA, Ahuja AT (eds.). Springer, New York 2012; 41-60. 
4. Jarząb B, Sporny S, Lange D, et al. Diagnostyka i leczenie raka tarczycy - rekomendacje polskie. Endokrynol Pol 2010; 61: 518-68.

5. Anil G, Hegde A, Chong FH. Thyroid nodules: risk stratification for malignancy with ultrasound and guided biopsy. Cancer Imaging 2011; 28: 209-23.

6. Maloney E, Dougherty P, Dighe M, Relyea-Chew A. The development of a validated checklist for ultrasound-guided thyroid nodule fine-needle aspiration biopsies: preliminary results. Ultrasound Q 2015; 31: 159-65.

7. Burguera B, Gharib H. Thyroid incidentalomas. Prevalence, diagnosis, significance, and management. Endocrinol Metab Clin North Am 2000; 29: 187-203.

8. Papini E, Guglielmi R, Bianchini A, et al. Risk of malignancy in nonpalpable thyroid nodules: predictive value of ultrasound and color-Doppler features. J Clin Endocrinol Metab 2002; 87: 1941-6.

9. Bombil I, Bentley A, Kruger D, Luvhengo TE. Incidental cancer in multinodular goitre post thyroidectomy. S Afr J Surg 2014; 52: 5-9.

10. Campbell MJ, Seib CD, Candell L, et al. The underestimated risk of cancer in patients with multinodular goiters after a benign fine needle aspiration. World J Surg 2015; 39: 695-700.

11. Nowotwory złośliwe w Polsce. Krajowy Rejestr Nowotworów. Available from: www.onkologia.org.pl.

12. Hedinger C, Williams ED, Sobin LH. The WHO histolog ical classification of thyroid tumors: a commentary on the second edition. Cancer 1989; 63: 908-11.

13. Pezzolla A, Marzaioli R, Lattarulo S, et al. Incidental carcinoma of the thyroid. Int J Surg 2014; 12: 98-102.

14. Zhang L, Liu Z, Liu Y, Gao W, Zheng C. The clinical prognosis of patients with cNO papillary thyroid microcarcinoma by central neck dissection. World I Surg Oncol 2015; 13: 138.

15. Kazaure HS, Roman SA, Sosa JA. Aggressive variants of papillary thyroid cancer: incidence, characteristics and predictors of survival among 43,738 patients. Ann Surg Oncol 2012; 19: 1874-80.

16. Siegel R, DeSantis C, Virgo K, et al. Cancer treatment and survivorship statistics, 2012. CA Cancer J Clin 2012; 62: 220-41.

17. Kunreuther E, Orcutt J, Benson CB, et al. Prevalence and distribution of carcinoma in the uninodular and multinodular goiter. Presented at the $76^{\text {th }}$ Annual Meeting of the American Thyroid Association; 2004 Sept 29-Oct 3; Vancouver, British Columbia, Canada 2004.

18. Nam-Goong IS, Kim HY, Gong G, et al. Ultrasonography-guided fine-needle aspiration of thyroid incidentaloma: correlation with pathological findings. Clin Endocrinol 2004; 60: 21-8.

19. Hermus AR. Clinical manifestations and treatment of nontoxic diffuse and nodular goiter. In: Werner and Ingbar's the thyroid: a fundamental and clinical text. Braverman LE, Utiger RD, Ingbar SH, Werner SC (eds). Lippincott Williams \& Wilkins, Philadelphia 2000; 867.

20. Kim EK, Park CS, Chung WY, et al. New sonographic criteria for recommending fine-needle aspiration biopsy of nonpalpable solid nodules of the thyroid. AJR Am J Roentgenol 2002; 178: 687-91.

21. Pellegriti G, Scollo C, Lumera G, Regalbuto C, Vigneri R, Belfiore A. Clinical behavior and outcome of papillary thyroid cancers smaller than $1.5 \mathrm{~cm}$ in diameter: study of 299 cases. J Clin Endocrinol Metab 2004; 89: 3713-20.

22. Schlumberger MJ. Papillary and follicular thyroid cancer. N Engl J Med 1998; 5: 297-306.
23. Mazzaferri EL, Jhiang SM. Long-term impact of initial surgical and medical therapy on papillary and follicular thyroid cancer. Am J Med 1994; 97: 418-28.

24. Wartofsky L. Management of papillary microcarcinoma: primum non nocere? J Clin Endocrinol Metab 2012; 97 : 1169-72.

25. Chow SM, Law SC, Au SK, et al. Changes in clinical presentation, management and outcome in 1348 patients with differentiated thyroid carcinoma: experience in a single institute in Hong Kong, 1960-2000. Clin Oncol 2003; 15: 329-36.

26. Kim BK, Choi YS, Kwon HJ, et al. Relationship between patterns of calcification in thyroid nodules and histopathologic findings. Endocr J 2013; 60: 155-60.

27. Hambly NM, Gonen M, Gerst SR, et al. Implementation of evidence-based guidelines for thyroid nodule biopsy: a model for establishment of practice standards. AJR Am J Roentgenol 2011; 196: 655-60.

28. Pelizzo MR, Boschin IM, Toniato A, et al. Natural history, diagnosis, treatment and outcome of papillary thyroid microcarcinoma (PTMC): a mono-institutional 12-year experience. Nucl Med Commun 2004; 25: 547-52.

29. Sofferman RA. Fine needle aspiration cytology. In: Ultrasound of the Thyroid and Parathyroid Glands. Sofferman RA, Ahuja AT (eds). Springer, New York 2012; 187-207.

30. Crockett JC. The thyroid nodule: fine needle aspiration biopsy technique. J Ultrasound Med 2011; 30: 685-94.

31. Ergin AB, Saralaya S, Olansky L. Incidental papillary thyroid carcinoma: clinical characteristics and prognostic factors among patients with Graves' disease and euthyroid goiter, Cleveland Clinic experience. Am J Otolaryngol 2014; 35: 784-90.

32. Ito $\mathrm{Y}$, Uruno $\mathrm{T}$, Nakano $\mathrm{K}$, et al. An observation trial without surgical treatment in patients with papillary microcarcinoma of the thyroid. Ann Surg Oncol 2011; 18: 3430-6.

33. Baudin E, Travagli JP, Ropers J, et al. Microcarcinoma of the thyroid gland: the Gustave Roussy Institute experience. Cancer 1998; 83: 553-9.

34. Braga M, Graf H, Ogata A, Batista J, Hakim Neto CA. Aggressive behaviour of papillary microcarcinoma in a patient with Graves' disease initially presenting as cystic neck mass. J Endocrinol Invest 2002; 25: 250-3.

35. Yamashita H, Noguchi S, Murakami N, et al. Extracapsular invasion of lymph node metastasis. A good indicator of disease recurrence and poor prognosis in patients with thyroid microcarcinoma. Cancer 1999; 86: 842-9.

36. Appetecchia M, Scarcello G, Pucci E, Procaccini A. Outcome after treatment for papillary thyroid microcarcinoma. J Exp Clin Cancer Res 2002; 21: 159-64.

37. Wada N, Duh QY, Sugino K, et al. Lymph node metastasis from 259 papillary thyroid microcarcinomas: frequency, pattern of occurrence, and optimal strategy for neck dissection. Ann Surg 2003; 237: 399-407.

38. Shattuck TM, Westra WH, Ladenson PW, Arnold A. Independent clonal origins of distinct tumor foci in multifocal papillary thyroid carcinoma. N Engl J Med 2005; 352: 2406-12.

39. Hoang JK, Nguyen XV, Davies L. Overdiagnosis of thyroid cancer: answers to five key questions. Acad Radiol 2015; 22: 1024-9.

40. Vassiliou I, Tympa A, Arkadopoulos N, Nikolakopoulos F, Petropoulou T, Smyrniotis V. Total thyroidectomy as the single surgical option for benign and malignant thyroid disease: a surgical challenge. Arch Med Sci 2013; 9: 74-8. 